7. Tang TT, Segura AD, Oechler HW, et al. Inflammatory myofibrohistiocytic proliferation simulating sarcoma in children. Cancer. 1990; 65:1626-34

8. Amir R, Danahey D, Ferrer K, et al. Inflammatory myofibroblastic tumor presenting with tracheal obstruction in a pregnant woman. Am J Otolaryngol. 2002;23:362-7.
9. Li L, Cerilli LA, Wick MR. Inflammatory pseudotumor (myofibroblastic tumor) of the heart. Ann Diagn Pathol. 2002;6:116-21.

10. Pettinato G, Manivel JC, De Rosa N, Dehner LP. Inflammatory myofibroblastic tumor (plasma cell granuloma). Clinicopathologic study of 20 cases with immunohistochemical and ultrastructural observations. Am J Clin Pathol. 1990;94:538-46.

\title{
Intralobar sequestration: A rare cause of severe hemothorax
}

\author{
W. Wandschneider, MD, a and H. Illiasch, MD, ${ }^{b}$ Klagenfurt, Austria
}

A

22-year-old male patient was admitted to our emergency room with signs of severe hemorrhagic shock. Hemotocrit was $7.5 \%$ and red blood cell count was 2.7 million. After hemodynamic stabilization with plasma expanders and 3 units of packed red cells, the patient gave a history of sudden severe pain in the left hemothorax with dyspnea and growing dizziness. There was no trauma or signs of infection, no cough, and no hemoptysis. Emergency chest radiography showed an opaque left hemothorax with slight shifting of the mediastinum to the right.

Computed tomography (CT) scan showed pleural effusion in the left thoracic cavity and a mass in the median left lower lobe, which was suspicious of an intralobar sequestration. We therefore performed an angiography to assess the presence of this malformation and find the feeding vessel. The angiogram revealed a large vessel deriving from the abdominal aorta, perforating the left diaphragm, and supplying an intrapulmonary sequestration. A leak of contrast medium proved bleeding from this vessel into the pleural cavity (Figure 1). The vessel was immediately occluded with multiple coils. The control showed an occluded vessel with no contrast effusion (Figure 2).

After the occlusion the patient was taken to the operating room where a video-assisted thoracoscopy (VATS) was performed. Blood and thrombi were evacuated and the pleural cavity inspected. There was no more bleeding and the feeding artery could not be detected. A thoracoscopic resection of the median segment of the left lower lobe (segment 10) was performed.

Due to his blood loss, the patient postoperatively developed an acquired respiratory distress syndrome requiring 6 days of mechanical ventilation. The further course was uneventful; the patient

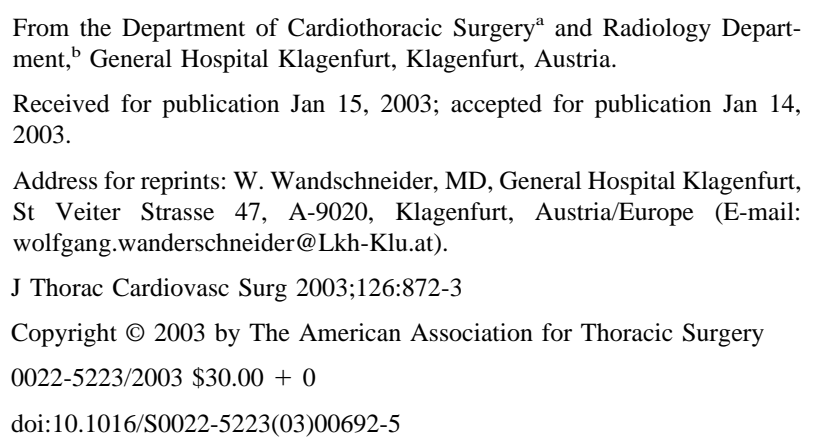

was transferred from the intensive care unit to the normal ward on day 9 and left the hospital on day 15. After 6 months his chest radiographs show adhesions in the left costophrenic sulcus with normal forced expiratory volume in 1 second, and the patient is currently without symptoms.

\section{Discussion}

A sequestration is a pulmonary malformation where pulmonary tissue is formed without a connection to the normal bronchial system, either within the lung (usually the lower lobe) or as a separate adjunct. Usually the sequestration has its own feeding artery deriving from the aorta. As sequestrations are most commonly located in the lower lobes, the artery frequently has its offspring from the abdominal aorta or splenic artery and perforates the diaphragm. As the systemic blood pressure in the sequestral artery is higher than the pulmonary artery pressure in the surrounding lung tissue, bleeding into the tissue is a well-known complication of this malformation. ${ }^{1,2}$ When the tissue communicates with a bronchus or bronchiolus, hemoptysis is possible. There are, however, only 2 reports in the recent literature ${ }^{1,3}$ of hemothorax as a consequence of bleeding into the pleural cavity.

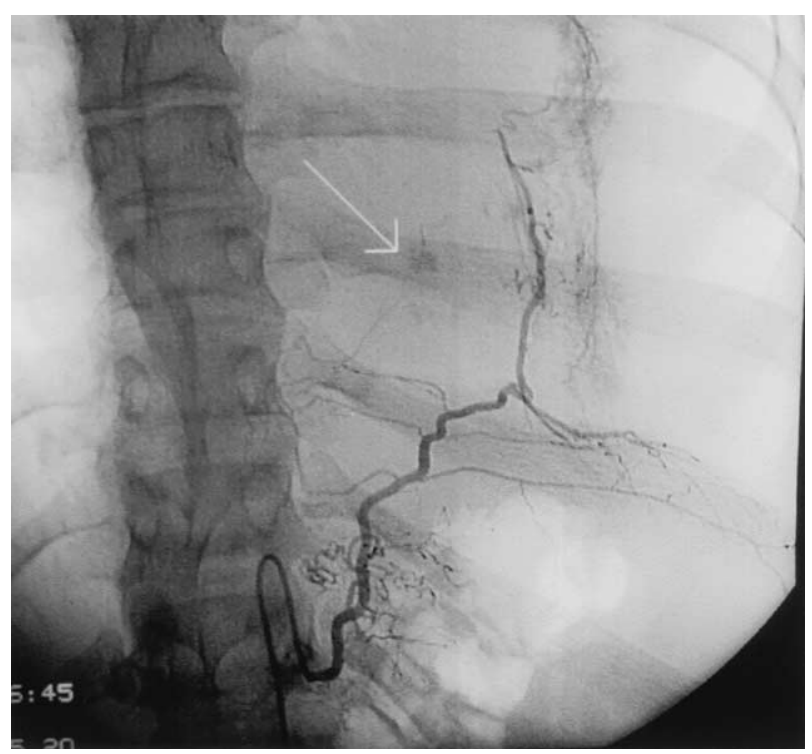

Figure 1. Angiography shows bleeding from the feeding vessel. 


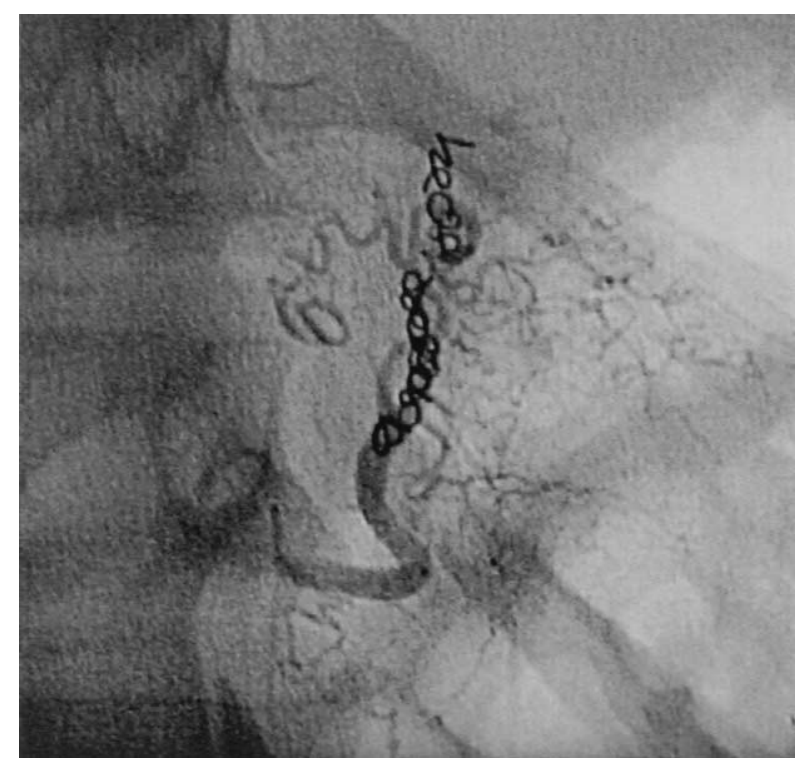

Figure 2. Thrombotic occlusion after embolization with coils.

When bleeding from a sequestral artery is found, interventional angiographic control is the safest and most rapid therapy. Coils or pellets can be selectively applied into the vessel, thus impeding blood flow and causing intravasal thrombus. This is also the method of choice when a sequestration is found to cause hemoptysis. ${ }^{4}$ Surgical ligation of the vessel is also feasible and is often combined with resection of the sequestration. Resection of the malformation is advocated in every case where complications occur. If the indication is hemoptysis, artery ligation should be combined with resection to prevent infection. ${ }^{1}$ Whether an asymptomatic sequestration found by chance is an indication for operation is still controversial. ${ }^{5}$ VATS segmentectomy offers a less invasive alternative to thoracotomy and yields better cosmetic results in this young patient group.

Hemothorax caused by a pulmonary sequestration is very rare. However, in the absence of trauma or other causes for pleural bleeding, this possibility should be kept in mind. CT scan, aortic angiography, or both can aid in diagnosis. Catheter embolization of the bleeding vessel is the method of choice. In every case resection of the sequestration, preferably by VATS, is advocated to prevent further complications.

\section{References}

1. Oxman LM. Intralobar sequestration causing hemoptysis and hemothorax. N Y State J Med. 1974;74:961-2.

2. Rubin EM, Garcia H, Horowith MD, Guerra JJ. Fatal massive hemoptysis secondary to intralobar sequestrations. Chest. 1994;106:954-5.

3. Zapatero J, Baamonde C, Bellan JM, et al. Hemothorax as rare presentation of intralobar pulmonary sequestration. Scand J Thorac Cardiovasc Surg. 1983;17:177-9.

4. Curros F, Chigot V, Emond S, et al. Role of embolisation in the treatment of bronchopulmonary sequestration. Pediatr Radiol. 2000;30: 769-73.

5. Nakamura H, Makihara K, Taniguchi Y, Ishiguro K, Ohgi S. Thoracoscopic surgery for intralobar pulmonary sequestration. Ann Thorac Cardiovasc Surg. 1999;5:405-7. 